\title{
OPTIMUM AND RISK-CLASS PRICING OF ANNUITIES
}

\author{
EYTAN SHESHINSKI
}

CESIFO WORKING PAPER No. 873

CATEgory 1: Public FinANCE

FEBRUARY 2003

An electronic version of the paper may be downloaded

- from the SSRN website: www.SSRN.com

- from the CESifo website: www.CESifo.de 


\title{
OPTIMUM AND RISK-CLASS PRICING OF ANNUITIES
}

\begin{abstract} view.

JEL Code: D8, G23, H55.

\author{
Eytan Sheshinski \\ The Hebrew University of Jerusalem \\ Department of Economics \\ Mount Scopus \\ Jerusalem 91905 \\ Israel \\ mseytan@mscc.huji.ac.il
}

When information on longevity (survival functions) is unknown early in life, individuals have an interest to insure themselves against future 'risk-class' classification. Accordingly, the First-Best typically involves transfers across states of nature. Competitive equilibrium cannot provide such transfers if insurance firms are unable to precommit their customers. On the other hand, public insurance plans that do not distinguish between 'risk-class' realizations are also inefficient. It is impossible, a-priori, to rank these alternatives from a welfare point of

This paper was presented at the CESifo conference on Pensions, Munich, May 2-3, 2001. 


\section{Demand for Annuities}

Consider an individual who wants to decide on his or her optimum consumption at different ages and choose an age for retirement in the presence of uncertainty about the length of life. Assume at first that this uncertainty is represented by a known survival distribution function, $F(z)$, which is the probability to survive to age $z$. Subsequently we shall analyze the more realistic case of uncertain survival probabilities early in life.

Let $T$ be maximum lifetime. ${ }^{1}$ Then, $F(0)=1, F(T)=0$ and $F(z)$ is non-increasing in $z$.

Assume that $f(z)$, the density of $1-F(z)$ (the probability of dying at age $z$ ), exists for all $z, 0 \leq z \leq T$. Consumption at age $z$ is denoted by $c(z)$. Utility of consumption, $u(c)$, is independent of age, increasing in $c$, and displays risk aversion $\left(u^{\prime}(c)>0\right.$ and $\left.u^{\prime \prime}(c)<0\right)$. When working, the individual provides one unit of labor. Disutility of work, $a(z)$, is independent of consumption and increasing with age $\left(a^{\prime}(z)>0\right)$. Contingent on survival, individuals work between age zero and $R$, i.e. retirement occurs at $R$.

The individual's objective is to maximize expected lifetime utility, $V$. With no subjective discount rate,

$$
V=\int_{0}^{T} F(z) u(c(z)) d z-\int_{0}^{R} F(z) a(z) d z .
$$

Let wages at age $z$ be $w(z)$. Savings, $w(z)-c(z)$, whether positive or negative, are assumed to incur a zero rate of interest. ${ }^{2}$

With no bequest motive, individuals save only in order to finance consumption, particularly during retirement. This is achieved efficiently by continuously annuitizing savings through the purchase of 'deferred-annuities' that will start payments upon retirement (Sheshinski (1999)).

Expected lifetime consumption is equal to expected lifetime income:

$$
\int_{0}^{T} F(z) c(z) d z-\int_{0}^{R} F(z) w(z) d z=0 .
$$

\footnotetext{
${ }^{1}$ Formally, it is possible to allow $T=\infty$.

${ }^{2}$ It is well-known how to modify the results for positive rates of interest and subjective discount rates.
} 
Maximization of (1) subject to (2) yields an optimum constant consumption flow, $c(z)=c^{*}, 0 \leq z \leq T$ which depends on the age of retirement By (2),

$$
c^{*}=c^{*}(R)=\frac{W(R)}{\bar{z}}
$$

where $\bar{z}=\int_{0}^{T} F(z) d z$ is life-expectancy ${ }^{3}$ and $W(R)=\int_{0}^{R} F(z) w(z) d z$ is expected wages until retirement.

The condition for optimum retirement is written:

$$
\phi(R)-a(R)=0
$$

where $\phi(R)=u^{\prime}\left(c^{*}(R)\right) w(R)$ is the additional utility from a small postponement of retirement. Condition (4) determines optimum retirement so as to balance these benefits against instantaneous labor disutility, $a(R)$. We assume that $w^{\prime}(R) \leq 0$. This ensures that (4) has a unique solution, denoted $R^{*}$, which satisfies second-order conditions. ${ }^{4}$

Optimum expected utility, $V^{*}$, is

$$
V^{*}=u\left(c^{*}\left(R^{*}\right)\right) \bar{z}-\int_{0}^{R^{*}} F(z) a(z) d z .
$$

Fully insuring against lifetime uncertainty, $c^{*}, R^{*}$ and $V^{*}$ are the First-Best allocation.

${ }^{3}$ Integrating by parts: $\int_{0}^{T} F(z) d z=\int_{0}^{T} z f(z) d z$.

${ }^{4}$ The sufficient condition is that at any solution, $R^{*}$, to (4), $\phi$ strictly decreases:

$$
\frac{\phi^{\prime}\left(R^{*}\right)}{\phi\left(R^{*}\right)}=\frac{w^{\prime}\left(R^{*}\right)}{w\left(R^{*}\right)}-\sigma\left(R^{*}\right) \frac{w\left(R^{*}\right)}{W\left(R^{*}\right)} F\left(R^{*}\right)<0
$$

where $\sigma=-\frac{u^{\prime \prime}(c) c}{u^{\prime}(c)}>0$. This condition clearly holds when $w^{\prime}(R) \leq 0$. 


\section{2 'Risk-Classes': Ranking of Survival Functions}

Individuals who share a common survival function are called a 'risk-class'. We want to consider a population that consists of a number of risk-classes and analyze the implications of alternative annuity pricing schemes in the presence of such heterogeneity. It will be useful first to formalize the notion that one survival function has a shorter life-span or is more 'risky' than another. Our approach is a direct application of the theory of Stochastic-Dominance.

\subsection{Ranking of Survival Function}

Consider two survival functions, $F_{1}(z)$ and $F_{2}(z), 0 \leq z \leq T$, both satisfying $F_{i}(0)=1, F_{i}(T)=0$ and $F_{i}(z)$ non-increasing in $z, i=1,2$. The conditional probability of dying at age $z, \frac{f_{i}(z)}{F_{i}(z)}$, is termed the 'Hazard-Rate' of $F_{i}(z)$.

Definition 1. ('Single Crossing' or 'Stochastic-Dominance'): The function $F_{1}(z)$ is said to (strictly) stochastically dominate $F_{2}(z)$ if the 'Hazard-Rates' satisfy

$$
\frac{f_{2}(z)}{F_{2}(z)}>\frac{f_{1}(z)}{F_{1}(z)}, \quad 0 \leq z \leq T .
$$

In words, the rate of decrease of survival probabilities, $\frac{d \ln F(z)}{d z}=-\frac{f(z)}{F(z)}$, is smaller at all ages with distribution 1 than with 2 .

Two implications of this definition are important. First, consider the functions $\frac{F_{i}(z)}{T}, 0 \leq z \leq T, i=1,2$. Being positive and their integral over $(0, T)$ equal $\int_{0}^{T} F_{i}(z) d z$

to one, they must intersect (cross) at least once over this range. At any such crossing, when $\frac{F_{1}(z)}{\int_{0}^{T} F_{1}(z) d z}=\frac{F_{2}(z)}{\int_{0}^{T} F_{2}(z) d z}$, condition (6) implies that $\frac{d}{d z}\left(\frac{F_{1}(z)}{\int_{0}^{T} F_{1}(z) d z}\right)>$ $\frac{d}{d z}\left(\frac{F_{2}(z)}{\int_{0}^{T} F_{2}(z) d z}\right)$. Hence, there can be only a single crossing. That is, there exists an age $z_{c}, 0<z_{c}<T$, such that (Figure 1 ), 


$$
\frac{F_{1}(z)}{\int_{0}^{T} F_{1}(z) d z} \lesseqgtr \frac{F_{2}(z)}{\int_{0}^{T} F_{2}(z) d z} \text { as } z \lesseqgtr z_{c} \text {. }
$$

Intuitively, (7) means that the dominant (dominated) distribution has higher (lower) survival rates, relative to life expectancy, at older (younger) ages.

Second, since $F_{i}(0)=1, i=1,2$, it follows from $(7)$ that

$$
\bar{z}_{1}=\int_{0}^{T} F_{1}(z) d z>\int_{0}^{T} F_{2}(z) d z=\bar{z}_{2},
$$

i.e., stochastic dominance implies higher life expectancy.

\subsection{Risk-Class Pricing of Annuities}

Suppose that the population consist of two risk classes represented by survival functions $F_{i}(z), i=1,2$. Otherwise individuals are identical (i.e., same preferences and incomes). Assume that group 1's survival function stochastically dominates, according to (6), that of group 2. In particular, group 1 has a higher life expectancy. In a perfectly competitive market, when firms can identify annuity purchasers according to the riskclass to which they belong, the analysis in section 2 applies to each group separately. This leads us to the following:

Proposition 1. When $F_{1}(z)$ stochastically dominates $F_{2}(z)$, then $c_{1}^{*}\left(R_{1}^{*}\right)<c_{2}^{*}\left(R_{2}^{*}\right)$ and $R_{1}^{*}>R_{2}^{*}$.

Proof. Applying (3) to each group, $c_{i}^{*}=c_{i}^{*}(R)=\frac{\int_{0}^{R} F_{i}(z) w(z) d z}{\int_{0}^{T} F_{i}(z) d z}, i=1,2$.

By (7),

$$
c_{i}^{*}(R)=\frac{\int_{0}^{R} F_{1}(z) w(z) d z}{\int_{0}^{T} F_{1}(z) d z}<\frac{\int_{0}^{R} F_{2}(z) w(z) d z}{\int_{0}^{T} F_{2}(z) d z}=c_{2}^{*}(R)
$$


for all $R, 0<R<T$. It follows from (4) that $\phi_{1}(R)>\phi_{2}(R)$ and hence, since $a^{\prime}(R)>0$, that $R_{1}^{*}>R_{2}^{*}$ and, further more, since $w^{\prime}(R) \leq 0$ and $a^{\prime}(R)>0, c_{1}^{*}\left(R_{1}^{*}\right)<$ $c_{2}^{*}\left(R_{2}^{*}\right) ॥$.

When wages are the same for all individuals, those with higher life expectancy partially compensate for higher longevity by retiring later, but their optimum consumption remains lower throughout.

\section{Uncertain Future Survival Functions}

The assumption that uncertainly in lifetime duration is represented by a known survival function is not realistic. Survival probabilities are difficult to predict, particularly early in life, since they depend on health and other circumstances which only unfold overtime. Accordingly, we shall now assume that early in life individuals do not know to what risk class they will belong later on. Consequently, they have an interest in insurance against alternative risk classifications later in life. Such insurance typically involves transfers across different risk classes ('states of nature') and is actuarially fair on average.

Risk classes with higher than average life expectancy face unfavorably priced annuities while the others face favorably priced annuities. It is desirable to have ex-ante insurance that allows consumption levels and retirement ages to deviate from those that would be chosen when annuity prices are actuarially fair for each risk class separately. ${ }^{5}$

We model the uncertainty about future risk classification as follows. All individuals have the same known survival function, $F(z)$, between ages zero to $M$, well before retirement. At that age, there is a probability $p, 0<p<1$, that the survival function becomes $F_{1}(z)$ and $1-p$ that it becomes $F_{2}(z)$.

Assuming that preferences do not vary with the realized risk class, expected lifetime utility is

\footnotetext{
${ }^{5}$ More generally, this applies not only to retirement but to other labor supply attributes (e.g., hours of work and effort) not modelled here.
} 


$$
\begin{gathered}
V=\int_{0}^{M} F(z) u(c(z)) d z+p \int_{M}^{T} F_{1}(z) u\left(c_{1}(z)\right) d z+(1-p) \int_{M}^{T} F_{2}(z) u\left(c_{2}(z)\right) d z- \\
\quad-\int_{0}^{M} F(z) a(z) d z-p \int_{0}^{R_{1}} F_{1}(z) a(z) d z-(1-p) \int_{M}^{R_{2}} F_{2}(z) a(z) d z
\end{gathered}
$$

where $c_{i}(z), M \leq z \leq T$, and $R_{i}$ are consumption and retirement age under realization of survival function $i, i=1,2$. Choices obey a zero expected profits constraint:

$$
\begin{gathered}
\int_{0}^{M} F(z) c(z) d z+p \int_{M}^{T} F_{1}(z) c_{1}(z) d z+(1-p) \int_{M}^{T} F_{2}(z) c_{2}(z) d z- \\
-\int_{0}^{M} F(z) w(z) d z-p \int_{0}^{R_{1}} F_{1}(z) w(z) d z-(1-p) \int_{M}^{R_{2}} F_{2}(z) w(z) d z=0
\end{gathered}
$$

Maximization of (10) subject to (11) yields optimum consumption, which is constant at all ages and across states: $c(z)=c_{1}(z)=c_{2}(z)=c^{*}$. Similarly, optimum retirement ages are equal for both risk classes: $R_{1}=R_{2}=R$. By (11), $c^{*}$ is given, in analogy to (3), by

$$
c^{*}=c^{*}(R)=\beta \frac{W_{1}(R)}{\bar{z}_{1}}+(1-\beta) \frac{W_{2}(R)}{\bar{z}_{2}},
$$

where $\bar{z}_{i}=\int_{0}^{M} F(z) d z+\int_{M}^{T} F_{i}(z) d z$ is life expectancy and $W_{i}(R)=\int_{0}^{M} F(z) w(z) d z+$ $\int_{M}^{R} F_{i}(z) w(z) d z$ is expected wages until retirement in state $i$, and $\beta=\frac{p \bar{z}_{1}}{p \bar{z}_{1}+(1-p) \bar{z}_{2}}$, $0<\beta<1$. Optimum retirement age, $R^{*}$, is determined, as before, by condition (4).

We state this result in the following:

Proposition 2. When preferences are independent of survival function realizations, optimum consumption is uniform and retirement ages are identical for all risk classes.

The optimum described above entails transfers across risk classes. 
Let $T_{i}^{*}$ be the optimum transfer to risk-class $i$, defined as the excess of expected consumption over expected wages from age $M$ to $T$ less expected total savings, $S^{*}$, during ages zero to $M, S^{*}=\int_{0}^{M} F(z)\left(w(z)-c^{*}\right) d z$ :

$$
T_{i}^{*}=c^{*} \int_{M}^{T} F_{i}(z) d z-\int_{M}^{R^{*}} F_{i}(z) w(z) d z-S^{*}=c^{*} \bar{z}_{i}-W_{i}\left(R^{*}\right) .
$$

By (12),

$$
\begin{aligned}
& T_{1}^{*}=\bar{z}_{1}(1-\beta)\left[\frac{W_{2}\left(R^{*}\right)}{\bar{z}_{2}}-\frac{W_{1}\left(R^{*}\right)}{\bar{z}_{1}}\right] \\
& T_{2}^{*}=\bar{z}_{2} \beta\left[\frac{W_{1}\left(R^{*}\right)}{\bar{z}_{1}}-\frac{W_{2}\left(R^{*}\right)}{\bar{z}_{2}}\right]
\end{aligned}
$$

By (7), transfers to the stochastically dominant (dominated) group are positive (negative), $T_{1}^{*}>0\left(T_{2}^{*}<0\right)$. The break-even constraint (11) entails that total expected transfers are zero: $p T_{1}^{*}+(1-p) T_{2}^{*}=0$.

\section{Competitive Markets: Risk-Class Pricing without Transfers}

We have seen that the First-Best allocation entails transfers across risk-classes. Competitive insurance markets can implement such a scheme provided that insurance firms can precommit their customers, prior to 'risk-class' realization, to stay-on until retirement. This is not plausible. Firms will successfully lure individuals with a short life expectancy, offering them actuarially fair annuities with no transfers to other groups. Consequently, in the absence of transfers between risk-classes, individuals at early ages find themselves not being insured against alternative risk classifications at later ages. We want to study the implications of this market failure.

At age $\mathrm{M}$, expected utility of an individual who belongs to risk class $i$, denoted $V_{i}$, is

$$
V_{i}=\int_{M}^{T} F_{i}(z) u\left(c_{i}(z)\right) d z-\int_{M}^{R_{i}} F_{i}(z) a(z) d z, \quad i=1,2 .
$$


When annuity prices are actuarially fair for each risk class, the zero expected profits constraint is

$$
\int_{M}^{T} F_{i}(z) c_{i}(z) d z-\int_{M}^{R_{i}} F_{i}(z) w(z) d z-S=0, \quad i=1,2
$$

where $S$, savings during ages zero to $M$, are the same for both risk classes. As before, maximization of (15) subject to (16) yields optimum consumption, which is constant at all ages: $c_{i}(z)=\widehat{c}_{i}, M \leq z \leq T$. By (16),

$$
\widehat{c}_{i}=\widehat{c}_{i}\left(R_{i}, S\right)=\frac{\int_{M}^{R_{i}} F_{i}(z) w(z) d z+S}{\int_{M}^{T} F_{i}(z) d z}, \quad i=1,2 .
$$

Optimal retirement age, denoted $\widehat{R}_{i}(S)$, is determined by the condition:

$$
\phi_{i}\left(R_{i}, S\right)-a\left(R_{i}\right)=0, \quad i=1,2
$$

where $\phi_{i}\left(R_{i}, S\right)=u^{\prime}\left(\widehat{c}_{i}\left(R_{i}, S\right)\right) w\left(R_{i}\right)$. At the optimum, with $\widehat{c}_{i}\left(\widehat{R}_{i}(S), S\right)$ and $\widehat{R}_{i}(S)$, expected utility, (15), is written $\widehat{V}_{i}(S)$. By the envelope theorem, $\frac{d \widehat{V}_{i}}{d S}=u^{\prime}\left(\widehat{c}_{i}\right)$.

Expected utility at age zero, $V$, is

$$
V=\int_{0}^{M} F(z) u(c(z)) d z+p \widehat{V}_{1}(S)+(1-p) \widehat{V}_{2}(S) .
$$

Maximization of (19) subject to the constraint:

$$
S-\int_{0}^{M} F(z) w(z) d z+\int_{0}^{M} F(z) c(z) d z=0
$$

yields constant optimum consumption $c(z)=\widehat{c}, 0 \leq z \leq M$, where, by (20) 


$$
\widehat{c}=\widehat{c}(S)=\frac{\int_{0}^{M} F(z) w(z) d z-S}{\int_{0}^{M} F(z) d z} .
$$

Optimum savings has to satisfy the condition:

$$
u^{\prime}(\widehat{c})=p u^{\prime}\left(\widehat{c}_{1}\right)+(1-p) u^{\prime}\left(\widehat{c}_{2}\right)
$$

At the optimum, marginal utility of consumption between age zero and $M$ is a weighted average of optimum marginal utility of consumption of the two risk classes.

Since $F_{1}(z)$ stochastically dominates $F_{2}(z)$, it is seen from (17) that for any $R$ and $S, \widehat{c}_{1}(R, S)<\widehat{c}_{2}(R, S)$. This implies, in turn, that $\phi_{1}(R, S)>\phi_{2}(R, S)$. It now follows from condition (18) that $\widehat{R}_{1}>\widehat{R}_{2}$ and (since $\left.w^{\prime}(R) \leq 0\right)$ that $\widehat{c}_{1}\left(\widehat{R}_{1}, S\right)<\widehat{c}_{2}(\widehat{R}, S)$.

We summarize:

Proposition 3: Risk class pricing without transfers implies that at the optimum, $\widehat{c}_{1}<\widehat{c}<\widehat{c}_{2}$ and $\widehat{R}_{1}>\widehat{R}_{2}$.

Comparing (12) with (17) - (18), it can be inferred that First-Best consumption and retirement, $\left(c^{*}, R^{*}\right)$, relate to optimum consumption and retirement under risk class pricing without transfers, $\left(\widehat{c}_{i}, \widehat{R}_{i}\right), i=1,2$, as follows: $\widehat{c}_{1}<c^{*}<\widehat{c}_{2}$ and $\widehat{R}_{1}>R^{*}>$ $\widehat{R}_{2}$ (Figure 3). In the First-Best allocation, individuals fully insure themselves against risk classification via transfers across risk classes. In the absence of such transfers, individuals with high life expectancy choose to postpone retirement, thereby partially compensating for their lower lifetime consumption. The opposite holds for those with low life expectancy.

Propositions 2 and 3 imply that when preferences are independent of survival function realizations, optimum risk class pricing without transfers is inferior to optimum uniform annuity prices. Importantly, this suggests that social security systems which provide uniform benefits to retirees with the same earnings history and the same retirement age are preferred to private annuity markets which do not provide transfers across risk-classes. We now want to explore whether this conclusion changes when preferences depend on survival function realizations. 


\section{Welfare Ranking of Uniform vs. Risk-Class An- nuity Systems}

The inefficiency of risk-class pricing without transfers depends crucially on individuals' desirability to maintain, after the arrival of information about their 'risk-class' classification an optimum level of consumption and retirement age independent of riskclass. Such invariance entails positive and negative transfers across risk-classes. This result does not carry-over to the case when utility functions are state dependent.

Consider, for example, the case when disutility from work depends on the state of nature. Thus, let $a_{i}(z)$ be this disutility in state $i, i=1,2$. When $F_{1}(z)$ stochastically dominates $F_{2}(z)$, it is natural to assume that $a_{1}(z)<a_{2}(z)$, for all $z \geq M{ }^{6}$

Assuming that utility from consumption is independent of the state of nature, it can be shown that the First-Best entails constant consumption, $c^{*}$, given by

$$
c^{*}=c^{*}\left(R_{1}, R_{2}\right)=\beta \frac{W_{1}\left(R_{1}^{*}\right)}{\bar{z}_{1}}+(1-\beta) \frac{W_{2}\left(R_{2}^{*}\right)}{\bar{z}_{2}},
$$

while optimum retirement ages are determined by the conditions ${ }^{7}$

$$
u^{\prime}\left(c^{*}\left(R_{1}^{*}, R_{2}^{*}\right)\right) w\left(R_{i}^{*}\right)-a_{i}\left(R_{i}^{*}\right)=0, \quad i=1,2 .
$$

It is easy to see from $(23)-(24)$ that $R_{1}^{*}>R_{2}^{*}$.

Whether the optimum entails transfers can be seen (from (14)) to depend on the difference between $\frac{W_{1}\left(R_{1}^{*}\right)}{\bar{z}_{1}}$ and $\frac{W_{2}\left(R_{2}^{*}\right)}{\bar{z}_{2}}$, that is, on the difference in expected total wages until retirement relative to expected lifetime. This difference can have any sign. For example, let $F_{i}(z)=e^{-\alpha_{i}}$, and $w(z)=w$. Then the First-Best has no transfers iff $\alpha_{1} R_{1}^{*}=\alpha_{2} R_{2}^{*}$, i.e. if the elasticity of optimum retirement relative to expected lifetime is unity. More generally, transfers to any group can be positive or negative depending on the level of this elasticity.

\footnotetext{
${ }^{6}$ The relation between $\mathrm{a}_{i}(z)$, for $M \leq z$, and $a(z)$, for $0 \leq z \leq M$ is immaterial for our discussion.

${ }^{7}$ Second-order conditions can be shown to be satisfied.
} 
In principle, therefore, when First-Best transfers are zero or negligible, a private market for annuities without transfers will be efficient. On the other hand, if a public social security system does not allow the flexibility in retirement ages implied by the optimum, then the private market will be superior.

When utility of consumption is also state dependent then, in the First-Best, both optimum consumption levels and optimum retirement ages depend on risk-class realization. Hence, a social security system which provides uniform consumption (and/or) imposes equal retirement ages is, in general, not efficient.

We are led to the following conclusion:

Proposition 4. It is impossible to rank, from a welfare point of view, an annuitization system that provides a uniform plan (of consumption and retirement) to all risk classes and a competitive system based on risk-class pricing but without precommitment and hence no transfers.

\section{References}

[1] Sheshinski, E. (1999) "Annuities and Retirement", Department of Economics, The Hebrew University of Jerusalem. 


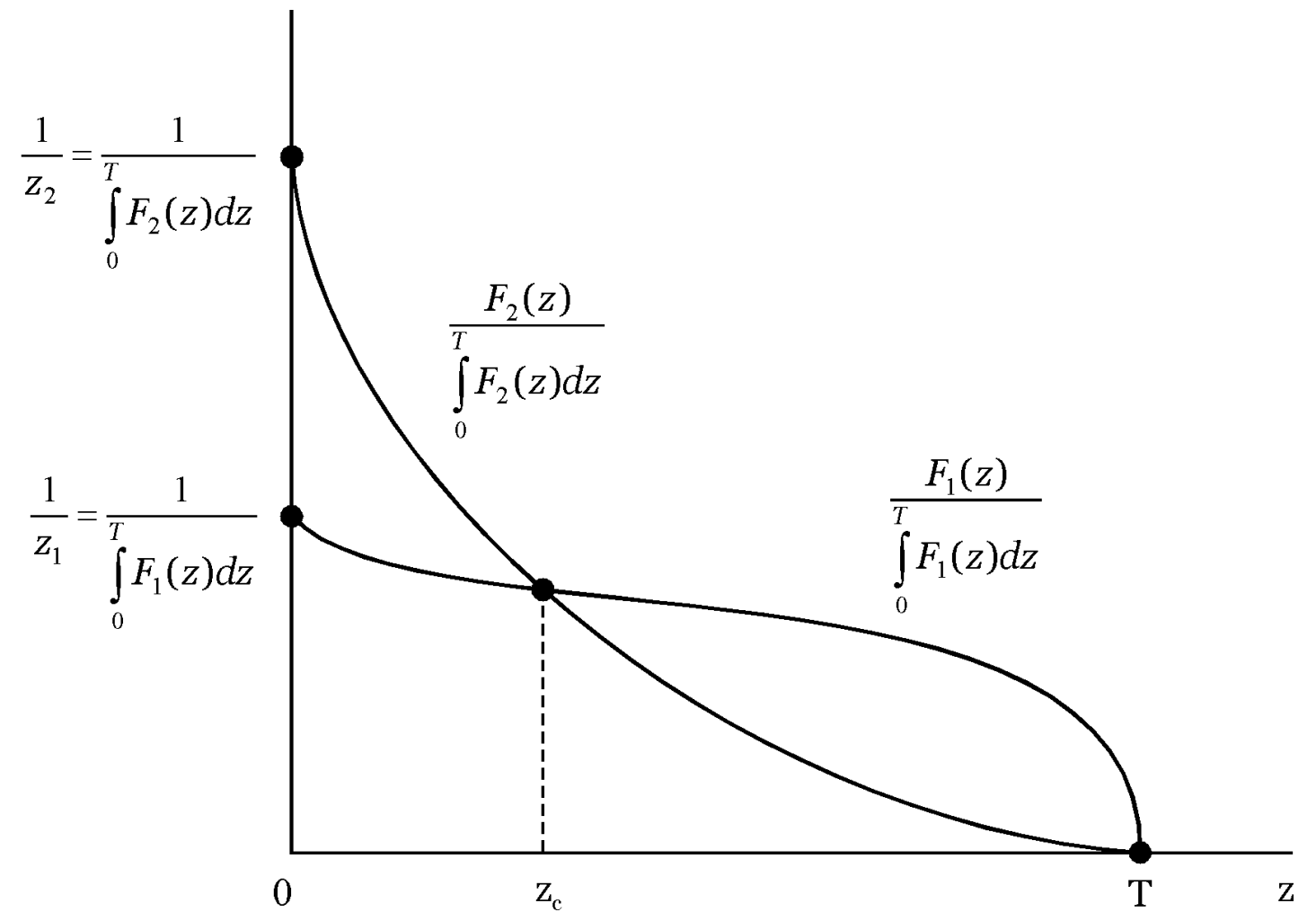

Figure 1: 


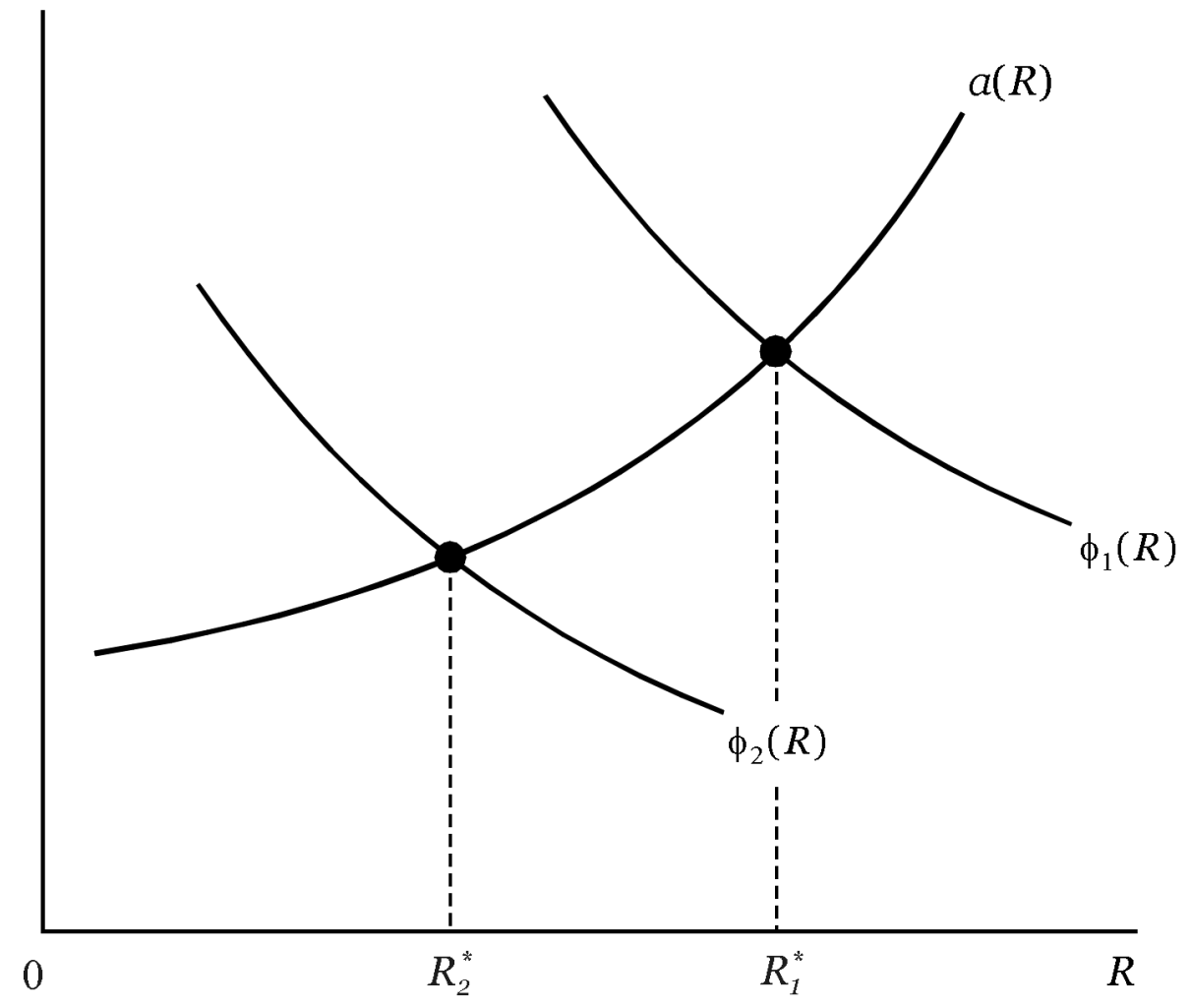

Figure 2: 


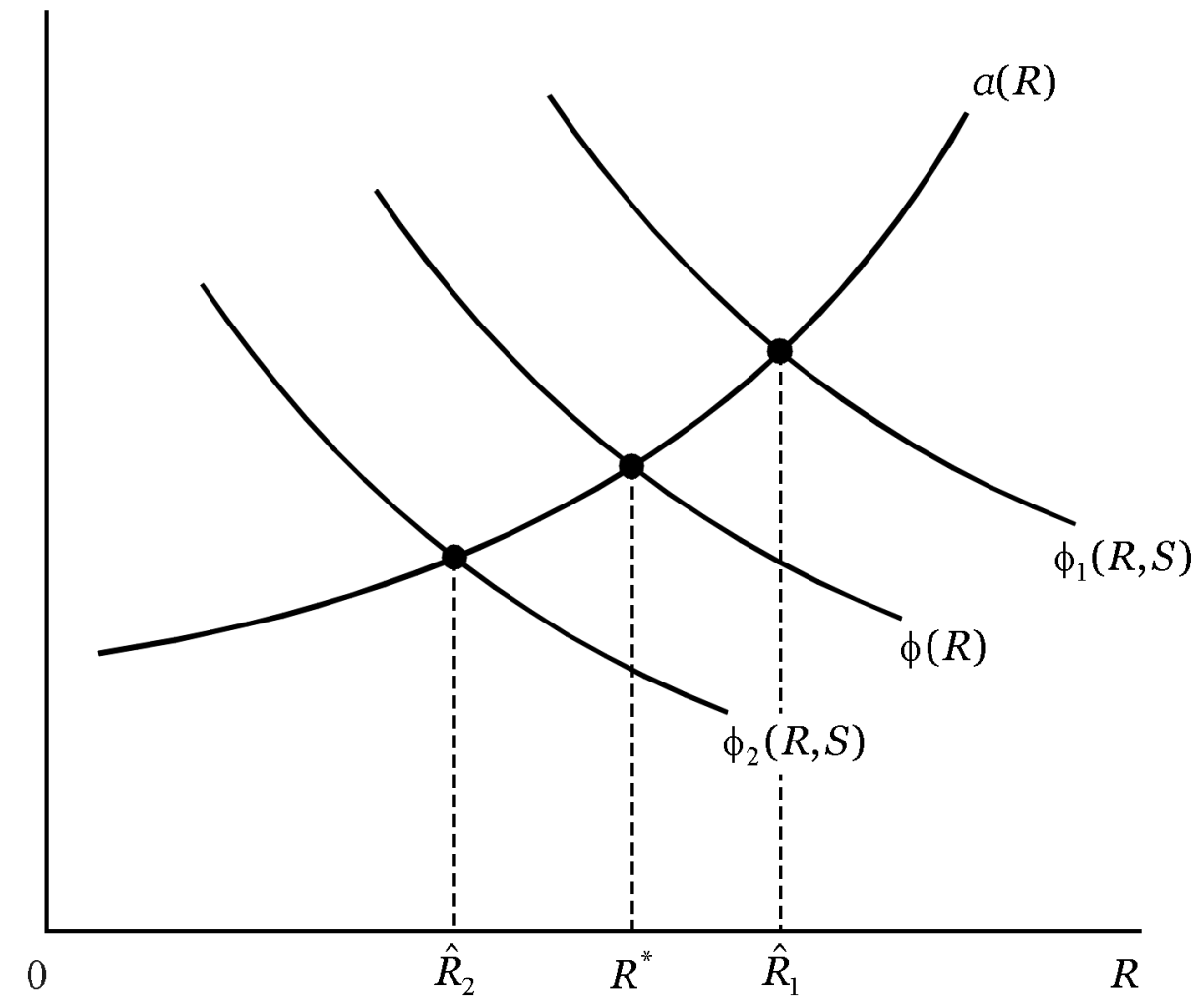

Figure 3: 


\title{
CESifo Working Paper Series
}

\author{
(for full list see www.cesifo.de)
}

809 Florian Englmaier and Achim Wambach, Contracts and Inequity Aversion, November 2002

810 Sarbajit Sengupta, Delegating Recruitment under Asymmetric Information, December 2002

811 Rajshri Jayaraman, On the Partial Public Provision of a Private Good, December 2002

812 Stéphanie Stolz, Banking Supervision in Integrated Financial Markets: Implications for the EU, December 2002

813 Christian Keuschnigg, Taxation of a Venture Capitalist with a Portfolio of Firms, December 2002

814 Inés Macho-Stadler and David Pérez-Castrillo, Settlement in Tax Evasion Prosecution, December 2002

815 Rainer Niemann and Dirk Simons, Costs, Benefits, and Tax-induced Distortions of Stock Option Plans, December 2002

816 Jan-Egbert Sturm and Barry Williams, Deregulation, Entry of Foreign Banks and Bank Efficiency in Australia, December 2002

817 V. Anton Muscatelli, Patrizio Tirelli, and Carmine Trecroci, Monetary and Fiscal Policy Interactions over the Cycle: Some Empirical Evidence, December 2002

818 Claude Hillinger, A General Theory of Price and Quantity Aggregation and Welfare Measurement, December 2002

819 Erkki Koskela and Ronnie Schöb, Optimal Capital Taxation in Economies with Unionised and Competitive Labour Markets, December 2002

820 Sheilagh Ogilvie, Guilds, Efficiency, and Social Capital: Evidence from German ProtoIndustry, December 2002

821 Hans Gersbach and Verena Liessem, Financing Democracy, December 2002

822 Costas Hadjiyiannis, Panos Hatzipanayotou, and Michael S. Michael, Optimal Tax Policies with Private-Public Clean-Up, Cross-Border Pollution and Capital Mobility, December 2002

823 François Ortalo-Magné and Sven Rady, Homeownership: Low Household Mobility, Volatile Housing Prices, High Income Dispersion, December 2002 
824 Syed M. Ahsan and Panagiotis Tsigaris, Measuring the Social Discount Rate under Uncertainty: A Methodology and Application, December 2002

825 Kai A. Konrad, Altruism and Envy in Contests: An Evolutionarily Stable Symbiosis, December 2002

826 Robert S. Chirinko and Huntley Schaller, A Revealed Preference Approach to Understanding Corporate Governance Problems: Evidence from Canada, December 2002

827 Geir B. Asheim, Green National Accounting for Welfare and Sustainability: A Taxonomy of Assumptions and Results, December 2002

828 Andrea Gebauer, Chang Woon Nam, and Rüdiger Parsche, Lessons of the 1999 Abolition of Intra-EU Duty Free Sales for Eastern European EU Candidates, December 2002

829 Giacomo Corneo, Work and Television, December 2002

830 Vivek H. Dehejia and Yiagadeesen Samy, Trade and Labour Standards - Theory, New Empirical Evidence, and Policy Implications, December 2002

831 Geir B. Asheim and Wolfgang Buchholz, A General Approach to Welfare Measurement through National Income Accounting, December 2002

832 Aaron Tornell and Frank Westermann, The Credit Channel in Middle Income Countries, January 2003

833 Gebhard Flaig, Time Series Properties of the German Monthly Production Index, January 2003

834 Campbell Leith and Jim Malley, Estimated Open Economy New Keynesian Phillips Curves for the G7, January 2003

835 Burkhard Heer and Bernd Süssmuth, Inflation and Wealth Distribution, January 2003

836 Erkki Koskela and Leopold von Thadden, Optimal Factor Taxation under Wage Bargaining - A Dynamic Perspective, January 2003

837 Carola Grün and Stephan Klasen, Growth, Income Distribution, and Well-Being: Comparisons across Space and Time, January 2003

838 Robert S. Chirinko and Ulf von Kalckreuth, On the German Monetary Transmission Mechanism: Interest Rate and Credit Channels for Investment Spending, January 2003

839 Sascha O. Becker, Andrea Ichino, and Giovanni Peri, How Large is the "Brain Drain" from Italy?", January 2003

840 Albert Berry and John Serieux, All About the Giants: Probing the Influences on Growth and Income Inequality at the End of the $20^{\text {th }}$ Century, January 2003 
841 Robert Fenge and Martin Werding, Ageing and the Tax Implied in Public Pension Schemes: Simulations for Selected OECD Countries, January 2003

842 Robert Fenge and Martin Werding, Ageing and Fiscal Imbalances Across Generations: Concepts of Measurement, January 2003

843 Giovanni Andrea Cornia, The Impact of Liberalisation and Globalisation on Income Inequality in Developing and Transitional Economies, January 2003

844 Peter Fredriksson and Per Johansson, Program Evaluation and Random Program Starts, January 2003

845 Bernd Hayo and Matthias Wrede, Fiscal Equalisation: Principles and an Application to the European Union, January 2003

846 Syed M. Ahsan and Jaideep Oberoi, Inequality, Well-being and Institutions in Latin America and the Caribbean, January 2003

847 Chang Woon Nam and Doina Maria Radulescu, The Role of Tax Depreciation for Investment Decisions: A Comparison of European Transition Countries, January 2003

848 V. Bhaskar and Steinar Holden, Wage Differentiation via Subsidised General Training, January 2003

849 Paloma Lopez-Garcia, Labour Market Performance and Start-up Costs: OECD Evidence, January 2003

850 Christian Keuschnigg and Soren Bo Nielsen, Public Policy for Start-up Entrepreneurship with Venture Capital and Bank Finance, January 2003

851 Yin-Wong Cheung, Menzie D. Chinn, and Eiji Fujii, China, Hong Kong, and Taiwan: A Quantitative Assessment of Real and Financial Integration, January 2003

852 Gregory D. Hess, The Economic Welfare Cost of Conflict: An Empirical Assessment, February 2003

853 Douglas J. Cumming and Jeffrey G. MacIntosh, Comparative Venture Capital Governance. Private versus Labour Sponsored Venture Capital Funds, February 2003

854 Eckhard Janeba and John Douglas Wilson, Decentralization and International Tax Competition, February 2003

855 Tapio Palokangas, Capital Accumulation and Employment Cycles in a Model of Creative Destruction, February 2003

856 Brendan Walsh, When Unemployment Disappears: Ireland in the 1990s, February 2003

857 Luis H. R. Alvarez and Erkki Koskela, A General Approach to the Stochastic Rotation Problem with Amenity Valuation, February 2003

858 Christian Schultz, Strategic Campaigns and Redistributive Politics, February 2003 
859 Ernst Fehr and Joseph Henrich, Is Strong Reciprocity a Maladaptation? On the Evolutionary Foundations of Human Altruism, February 2003

860 Haizhou Huang, Dalia Marin, and Chenggang Xu, Financial Crisis, Economic Recovery and Banking Development in Former Soviet Union Economies, February 2003

861 Pedro Cardoso and Bernard M.S. van Praag, How Sustainable Are Old-age Pensions in a Shrinking Population with Endogenous Labour Supply?, February 2003

862 Volker Meier, Efficient Transfer of Aging Provisions in Private Health Insurance, February 2003

863 Edward Castronova, Theory of the Avatar, February 2003

864 Robert S. Chirinko, Hans van Ees, Harry Garretsen, and Elmer Sterken, Investor Protections and Concentrated Ownership: Assessing Corporate Control Mechanisms in the Netherlands, February 2003

865 Bernard M.S. van Praag and Pedro Cardoso, The Mix Between Pay-as-you-go and Funded Pensions and what Demography has to do with it, February 2003

866 Ernst Fehr, Urs Fischbacher, Bernhard von Rosenbladt, Jürgen Schupp, and Gert G. Wagner, A Nation-Wide Laboratory. Examining Trust and Trustworthiness by Integrating Behavioral Experiments into Representative Survey, February 2003

867 Frank Heinemann, The Inflationary Impact of Wage Indexation, February 2003

868 Eytan Sheshinski, Bounded Rationality and Socially Optimal Limits on Choice in a Self-Selection Model, February 2003

869 M. Hashem Pesaran, Estimation and Inference in Large Heterogenous Panels with Cross Section Dependence, February 2003

870 Luis H. R. Alvarez and Erkki Koskela, On the Tree-Cutting Problem under Interest Rate and Forest Value Uncertainty, February 2003

871 Norbert Berthold and Rainer Fehn, Unemployment in Germany: Reasons and Remedies, February 2003

872 Clemens Fuest, Bernd Huber, and Philipp Tilleßen, Tax Policy and Entrepreneurship in the Presence of Asymmetric Information in Capital Markets, February 2003

873 Eytan Sheshinski, Optimum and Risk-Class Pricing of Annuities, February 2003 